\title{
Identification and Quantification of Phenolic Compounds in Mangifera Indica Waterlily Kernel and Their Free Radical Scavenging Activity
}

\author{
Al-Shwyeh Hussah Abdullah, Abdulkarim Sabo Mohammed, and Rasedee Abdullah \\ Universiti Putra Malaysia, 43400 Serdang, Selangor, Malaysia \\ Email: al-shwyeh-hussah@hotmail.com; \{karimsabo, rasedee $\}$ upm.edu.my \\ Mohamed Elwathiq Saeed Mirghani \\ Department of Biotechnology Engineering, Faculty of Engineering, International Islamic University Malaysia (IIUM), \\ Malaysia \\ Email: elwathig@iium.edu.my
}

\begin{abstract}
The aim of this study was to determine phenolic compounds and antioxidant capacity of extract prepared from Mangifera indica waterlily kernel. Acidified methanolic extract prepared from $M$. indica waterlily kernel was analyzed. The total phenolic content was determined by the Folin_Ciocalteu method. Antioxidant activity was measured by the 1,1-diphenyl-2-picrylhydrazyl (DPPH) radical scavenging activity and ferric-reducing antioxidant power (FRAP) assays. Characterization of phenolic compounds was conducted using HPLCDAD and TSQ-ESIMS and Peak identities were confirmed by comparing their retention times, UV_vis absorption spectra, and mass spectra with authentic standards. The total phenolic content of $M$. indica waterlily kernel was $8.6 \mathrm{mg} \mathrm{GAE} / \mathrm{g} \mathrm{DW}$. The seeds extract showed a strong potency of antioxidant activity as confirmed by the DPPH radical scavenging activity, .... and FRAP assays. Epigallocatechin (EGC), chlorogenic acid, apiginin, and epicatechin were the major compounds among the 12 phenolics that have been identified and quantified in $M$. indica waterlily kernel with $21.8,13.7,3.2$ and $2.7 \mathrm{mg} / \mathrm{g}$ $M$. indica waterlily kernel, respectively. The 12 phenolic compounds identified in $M$. indica waterlily kernel using HPLCDAD and TSQ-ESI-MS had high antioxidant activity and should be considered as a prospective antioxidant.
\end{abstract}

Index Terms-mangifera indica, phenolic compounds, antioxidants, bioactive analysis

\section{INTRODUCTION}

Oxidative stress, due to reactive oxygen species (ROS), is implicated in the development of many chronic diseases including diabetes mellitus and cancers [1]. Antioxidants have been demonstrated to play important roles in ROS scavenging via several mechanisms [2]. In particular, epidemiological studies have demonstrated that increased consumption of fruits and vegetables is associated with reduced risks of chronic diseases like cancers, likely due to their antioxidant-rich contents including phenolic compounds [3], [4]. There are over 500 mango varieties, mostly restricted to tropical Asia [5],

Manscript received August 29, 2014; revised December 21, 2014. which are commonly used as fruits and for other purposes. Peels and seeds are the major by- products generated during the processing of mango amounting from 35 to $60 \%$ of the total fruit weight [6]. In addition to the nutritional content of the fleshy parts of mangoes, [7] reported that mango peels contain valuable compounds, such as polyphenols, carotenoids and vitamins that are known to be antioxidant-rich. These antioxidants could scavenge radicals in biological systems leading to reduced risk of oxidative stress-related diseases. Furthermore, several studies have reported on the phenolics of Mangifera indica [8], [9]. However, to date there is still little information on phytochemical components of Mangifera indica waterlily kernel and their functional effects especially related to radical scavenging activity and antioxidant properties. Thus the aim of this study was to evaluate the phenolic compounds from the extract of $\mathrm{M}$. indica waterlily kernel and their antioxidant potentials.

\section{MATERIALS AND METHOD}

\section{A. Chemicals}

All standards (gallic acid, protocatechuic acid, pcoumaric acid, chlorogenic acid, ellagic acid, vanillic acid, 4-hydroxybenzoic acid, ferulic acid, methyl gallate, ethyl gallate, (+)-catechin, mangiferin, morin, rutin, daidzein and kaempferol) used for identification and quantification were purchased from Sigma Aldrich Co. (St. Louis, MO, USA). Also, 2,4,6-Tripyridyl-S- triazine (TPTZ), Butylatedhydroxytoluene (BHT) and 1, 1diphenyl-2-picrylhydrazyl (DPPH) were purchased from Fisher Scientific (Loughborough, UK) while the FolinCiocalteu reagent was obtained from Merck (Darmstadt, Germany). HPLC grade solvents were obtained from Fisher Scientific (Loughborough, UK).

\section{B. Preparation of Standard Curves}

The standard stock solutions were prepared by dissolving standards in methanol to a concentration of 
$100 \mu \mathrm{g} / \mathrm{mL}$. For the calibration curves, four additional concentrations $(20,40,60$ and $80 \mu \mathrm{g} / \mathrm{mL}$ methanol) were prepared by the dilution of the stock solutions with methanol.

\section{Sample Preparation}

Mango fruits were procured from a local market at Kuala Lumpur in between the month of June to July, 2012. Extraction of samples- M. indica waterlily kernel was soaked in water, and washed to remove adhering flesh. They were then air-dried, and subsequently kept in an oven at $45{ }^{\circ} \mathrm{C}$ for $2 \mathrm{~d}$. The dried kernels were finely ground with a Waring blender 7011HS (Osaka Chemical Co. Ltd., Kita-Ku, Osaka, Japan) and stored at $4{ }^{\circ} \mathrm{C}$ until analysis. Ethanol $(95 \%)$ was added to the kernel powder at 10:1 (v/w) and the mixture shaken continuously at 200 $\mathrm{rpm}$ and $37^{\circ} \mathrm{C}$ for $24 \mathrm{~h}$ in an incubator shaker (INNOVA 4000, New Jersey, USA). Insoluble materials were then removed by filtration and the filtrates centrifuged for 10 min at $4000 \mathrm{rpm}$ using Benchtop Centrifuge Z200A (Labnet International, Inc., Woodbridge, NJ, USA). The residues were discarded and the supernatant dried using 1L Rotary Evaporator N1001S-WD (Tokyo Rikakikai Co., Ltd., Koishikawa Bunkyo-ku, Tokyo, Japan) until the extract was fully concentrated. Total polyphenols were extracted by adding $40 \mathrm{~mL}$ of methanol $(50 \%, \mathrm{v} / \mathrm{v})$ to $500 \mathrm{mg}$ of $\mathrm{M}$. indica waterlily kernel with constant shaking in an orbital shaker (Unimax 1010, Heidolph Instruments $\mathrm{GmbH} \& \mathrm{Co}$. KG, Germany) at $200 \mathrm{rpm}$ for $1 \mathrm{~h}$ at room temperature. Extracts were centrifuged at $1500 \mathrm{~g}$ for $10 \mathrm{~min}$ at $23{ }^{\circ} \mathrm{C}$ in a Hettichi centrifuge (Zentrifugen, Germany); $40 \mathrm{~mL}$ of acetone (70\% v/v) was then added to the residue with constant shaking for $1 \mathrm{~h}$ at room temperature and centrifuged at $1500 \mathrm{~g}$ for $10 \mathrm{~min}$ at $23{ }^{\circ} \mathrm{C}$. Supernatant extracts were combined and adjusted to $100 \mathrm{~mL}$ with distilled water [10]. Polyphenols were determined spectrophotometrically by the FolinCiocalteau method as described previously [11]. Briefly, $0.1 \mathrm{ml}$ of the sample extract was added to $0.75 \mathrm{ml}$ of Folin-Ciocalteu reagent followed by addition of $0.75 \mathrm{ml}$ of $6 \%$ sodium carbonate. The mixture was stirred and allowed to stand for $90 \mathrm{~min}$. The absorbance was read at $725 \mathrm{~nm}$ using a UV/Vis 1601 spectrophotometry (Shimadzu, Kyoto, Japan). A blank consisting of combined methanol $50 \%$ and acetone $70 \%(\mathrm{v} / \mathrm{v})$ and reagents was used as a control. The results were expressed as $\mathrm{mg} \mathrm{GAE} / \mathrm{g}$ of dry matter utilising a calibration curve of gallic acid at a concentration ranging from $0.02 \mathrm{mg} / \mathrm{ml}$ to $0.1 \mathrm{mg} / \mathrm{ml}$.

\section{Ferric-Reducing Antioxidant Power (FRAP) Assay}

The FRAP reagent was prepared freshly by mixing 10 volumes of $300 \mathrm{mmol} / \mathrm{L}$ acetate buffer, $\mathrm{pH} 3.6$ with 1 volume of $10 \mathrm{mmol} / \mathrm{L} \mathrm{TPTZ} \mathrm{(2,} \mathrm{4,} \mathrm{6-tripyridyl-s-triazine)}$ in $40 \mathrm{mmol} / \mathrm{L} \mathrm{HCl}$ and with 1 volume of $20 \mathrm{mmol} / \mathrm{L}$ $\mathrm{FeCl} 3.6 \mathrm{H} 2 \mathrm{O}$. The reagent was warmed to $37{ }^{\circ} \mathrm{C}$ and absorbance was read at $593 \mathrm{~nm}$ (A1) against deionized water as blank. Mangifera indica waterlily kernel extract and vitamin $\mathrm{C}$ as a positive control were dissolved in 10 $\mathrm{mL}$ of distilled water at 0 (control), 50,100, 200, 300 and $400 \mu \mathrm{g} / \mathrm{mL}$, then $50 \mu \mathrm{L}$ of sample and positive control and $150 \mu \mathrm{L}$ of deionized water were added to $1550 \mu \mathrm{L}$ of FRAP reagent. After adding the sample to the FRAP reagent, a second absorbance at $593 \mathrm{~nm}$ was read after 8 min (A2). Finally A1 was deducted from A2 to determine the FRAP value of the sample. A standard curve was plotted using different concentrations (100 -1000 $\mu \mathrm{mol} / \mathrm{L})$ of $\mathrm{FeSO}_{4} \cdot 7 \mathrm{H}_{2} \mathrm{O}$. The final results were expressed as the concentrations of antioxidants having a ferric-reducing capability equivalent to that of $1 \mu \mathrm{mol} / \mathrm{L} \mathrm{FeSO}_{4} .7 \mathrm{H}_{2} \mathrm{O}$ [12].

\section{E. 1, 1-Diphenyl-2-Picrylhydrazyl (DPPH) Assay}

The DPPH free radical-scavenging activity was evaluated by the method of Yang et al. [13]. M. indica waterlily kernel extract and BHT as a positive control were dissolved in $10 \mathrm{~mL}$ of distilled water at 0 (control), 50, 100, 150, 200 and $250 \mu \mathrm{g} / \mathrm{mL}$. Then, $1 \mathrm{~mL}$ of $\mathrm{M}$. indica waterlily kernel extract and BHT solutions was mixed with $2 \mathrm{~mL}$ of $0.2 \mathrm{mmol} / \mathrm{L} \mathrm{DPPH}$ (in ethanol) separately, after which each solution was mixed thoroughly and incubated at $25{ }^{\circ} \mathrm{C}$ for $20 \mathrm{~min}$ then absorbance was read spectrophotometrically at $517 \mathrm{~nm}$. The inhibition of DPPH radical by $\mathrm{M}$. indica waterlily kernel extract was calculated according to the following equation: Scavenging activity $(\%)=100-[$ As $/ \mathrm{A} 0 \mathrm{X}$ 100] As is the absorbance of the sample and $A 0$ is the absorbance of the blank control.

Chromatographic analysis- To obtain higher concentrations of the phenolic compounds, hydrolysis reaction for the samples was done as reported by Nuutila et al. [14]. Briefly, $500 \mathrm{mg}$ of M. indica waterlily kernel extract were placed in a test tube and extracted with 40 $\mathrm{mL}$ of acidified methanol $(4 \mathrm{~mL}$ of $\mathrm{HCl}$ was added to obtain a final concentration of $1.2 \mathrm{M}$ ) and $2 \mathrm{mg}$ ascorbic acid as an antioxidant. Samples were shaken at $240 \mathrm{rpm}$ on an orbital shaker at $35^{\circ} \mathrm{C}$ for $16 \mathrm{~h}$. Then, the mixture was centrifuged at $1500 \mathrm{x} \mathrm{g}$ for $10 \mathrm{~min}$, the supernatants were collected and brought to a final volume of $50 \mathrm{~mL}$ with deionized water. The hydrolyzed sample was stored at $-80^{\circ} \mathrm{C}$. Before use, the extract was filtered through a $0.45 \mu \mathrm{m}$ nylon membrane filter (SRP 15, Machery Nagel, Düren, Germany) and then analyzed by HPLC.

The HPLC method was validated in terms of the linearity of calibration curves that have been previously determined for the standards and the components in $\mathbf{M}$. indica waterlily kernel extract. Linearity of detector responses was determined on five concentration levels with three injections for each concentration. A linear relationship between peak area and concentration (20-100 $\mathrm{g} / \mathrm{mL}$ ) was observed for each standard with a correlation /coefficient ranging from $r=0.9912$ to $r=0.9993$.

The reproducibility of the injection integration procedure was determined for standards and for the twelve M. indica waterlily kernel extract components 112 (Fig. 2). The solutions of standards and samples were prepared 3 times and each solution was injected 3 times. The relative standard deviations of peak area for each compound with replicate injection were calculated.

Quantitative analysis of $\mathrm{M}$. indica waterlily kernel extract were performed on an Agilent series 1100 HPLC system (Agilent Technologies, Palo Alto, CA, USA) 
equipped with a diode array detector (DAD) following the procedure described by $\mathrm{He}$ and $\mathrm{Xia}$ (2007) [3]. Briefly, chromatographic analysis were performed on a Lichrospher C18, $5 \mu \mathrm{m}$ (250 mm x $4 \mathrm{~mm}$, i.d.) column from Merck (Darmstadt, Germany) utilizing a mobile phase consisting of $0.5 \%(\mathrm{v} / \mathrm{v})$ acetic acid (mobile phase A) and $100 \%$ methanol (mobile phase B) at a flow rate of $0.8 \mathrm{~mL} / \mathrm{min}$ with a gradient elution program and $30 \mathrm{~min}$ run time. The gradient elution started at $100 \%$ phase A with a linear decrease to $10 \%$ at $20 \mathrm{~min}$ to $25 \mathrm{~min}$, the next 5 min phase A increased back to $100 \%$. The injection volume was $20 \mu \mathrm{L}$ at $25^{\circ} \mathrm{C}$ oven temperature. The majority of the phenolic compounds in $\mathrm{M}$. indica waterlily kernel extract showed a UV-Vis spectra at 280 $\mathrm{nm}$, rather than 254, 320, and $365 \mathrm{~nm}$. When there were variations in retention times, peak identifications were supported by spiking with authentic standards or confirmed by LC-ESI-MS analysis.

\section{F. Mass Spectrometry}

Mass spectrometry (MS) is an analytical technique that measures the mass-to-charge ratio of charged particles. It is used for determining masses of particles, for determining the molecule and for elucidating the chemical structures of molecules, such as peptides, polyphenols and other chemical compounds. Electrospray ionization mass spectrometric (ESI-MS) analysis of phenolic compounds in M. indica waterlily kernel extract was performed to support phenolics identification using an applied TSQ Quantum Ultra- LCMS (Thermo Fisher, San Diego, CA, USA). The mass spectra were operated in both negative and positive electrospray ionization ESI modes and high resolution with extended resolution up to 3000 Daltons was used for the best resolution. The spray voltage used was $3500 \mathrm{~V}$. The sheath/ auxiliary /sweep gas was $99 \%$ pure nitrogen and sheath gas pressure was 30 psi with 5 psi for auxiliary gas pressure. The capillary temperature was $270{ }^{\circ} \mathrm{C}$. The injection volume was $10 \mu \mathrm{L}$ and the flush speed was $100 \mu \mathrm{L} / \mathrm{s}$.

A preliminary study of the UV spectrum of the peaks gave a first indication of the family of phenolic compounds. Thus, the surveyor method of PDA-LCMS was set as following: run time was $30 \mathrm{~min}$ with rise time $1 \mathrm{sec}$, scan wavelength was performed at $200-600 \mathrm{~nm}$; the scan bandwidth was $1 \mathrm{~nm}$ with scan rate of $5(\mathrm{~Hz})$ and scan step of $1 \mathrm{~nm}$. The channel sample rate was performed in $10(\mathrm{~Hz})$ with the three following channels: channel A, the wavelength was $214 \mathrm{~nm}$ and bandwidth was $9 \mathrm{~nm}$; channel B wavelength was $254 \mathrm{~nm}$ and $9 \mathrm{~nm}$ for bandwidth; channel C, $280 \mathrm{~nm}, 9 \mathrm{~nm}$ for wavelength and bandwidth, respectively. A gradient elution was performed with $0.2 \%(\mathrm{v} / \mathrm{v})$ acetic acid in deionized water as solvent $\mathrm{A}$ and $100 \%$ methanol as solvent $\mathrm{B}$ with the flow rate of $0.1 \mathrm{~mL} / \mathrm{min}$ according to the following program: first $20 \mathrm{~min}$, the linear gradient of solvent $\mathrm{A}$ was from $95 \%$ to $10 \%$ and $5 \%$ to $90 \%$ of solvent $\mathrm{B}$, the running was constant for $5 \mathrm{~min}$ and then linearly increasing from $10 \%$ to $95 \%$ for solvent A in contrast of solvent $90 \%$ to $5 \%$ for solvent B. In the MS analysis (full scan), data were collected over a mass of 100 to $800 \mathrm{~m} / \mathrm{z}$. Identification of the phenolic compounds of $\mathrm{M}$. indica waterlily kernel extract was achieved by comparison of their retention times, UV-Vis absorption spectra and mass spectra with authentic standards.

Statistical analysis- Each analysis was done in triplicate. Results were expressed as mean values \pm standard deviations. Data were statistically analysed by One-Way ANOVA procedure with SPSS software Version 19.0 (Chicago, IL USA), followed by the Duncan test. The confidence limits used in this study were based on $95 \%$ confidence $(\mathrm{p}<0.05)$.

\section{RESULTS AND DISCUSSIONS}

\section{A. Total Extractable Polyphenols (TEP)}

The content of TEP in the Mangifera indica waterlily kernel was $8.57 \pm 0.3 \mathrm{mg}$ gallic acid equivalents (GAE)/100 mg dry sample. The present results are in agreement with those reported previously. Ajila et al. [15] had reported $96 \mathrm{mg} \mathrm{GAE} / \mathrm{g}$ of Mangifera indica ripe peels, while other have reported higher (with amount at $102 \mathrm{mg}$ GAE/g) or slightly lower values (70 mg GAE/g) [16], [17]. This suggests that $M$. indica waterlily kernel is rich in polyphenol compounds. Interestingly, the total polyphenols in $M$. indica waterlily kernel extract estimated using Folin-Ciocalteau method showed different result compared to that calculated from the sum of the individual phenolic compounds using the HPLC method (53.6 mg/g d.w.). The higher value observed due to Folin-Ciocalteu method could be related to interference of sugars and protein [18]. As can be recalled, polyphenols have been associated with high antioxidant potentials and increased capacity for scavenging free radicals. The implication of such an effect is that fewer radicals due to the scavenging ability of polyphenols from foods like Mango kernel could protect against development of oxidative stress-related diseases caused by excess free radicals.

\section{B. FRAP}

The FRAP assay is traditionally used to assess the antioxidant potentials of extrascts from food or plants. In this study, the antioxidant capacities of $\mathrm{M}$. indica waterlily kernel extract and ascorbic acid as control were determined and are shown in Fig. 1. The M. indica waterlily kernel exhibited a high antioxidant power similar to what ascorbic acid produced. The highest concentration of $\mathrm{M}$. indica waterlily kernel used (400 $\mu \mathrm{g} / \mathrm{mL})$, showed an antioxidant power $(1289 \mu \mathrm{M} / \mathrm{L})$ that was comparable to what a similar concentration of ascorbic acid produced $(1324 \mu \mathrm{mol} / \mathrm{L})$. The current findings are higher than what was reported for the same concentration of Mangifera pajang Kort. pulp (770 $\mu \mathrm{mol} / \mathrm{L})[19]$. In addition, a study by Abu Bakar et al. [20] demonstrated that the antioxidant activity of unripe peel of Mangifera pajang Kort. using FRAP assay was 343.17 $\mu \mathrm{mol} / \mathrm{g}$ sample, also lower than what was found in the current study. This is likely due to complete ripening of the fruit studied in the current study, which may have enhanced the antioxidants higher than in unripe fruits. Moreover, studies have demonstrated that polyphenolic 
content of ripe mango peel is normally higher than the unripe peel [21], [22].

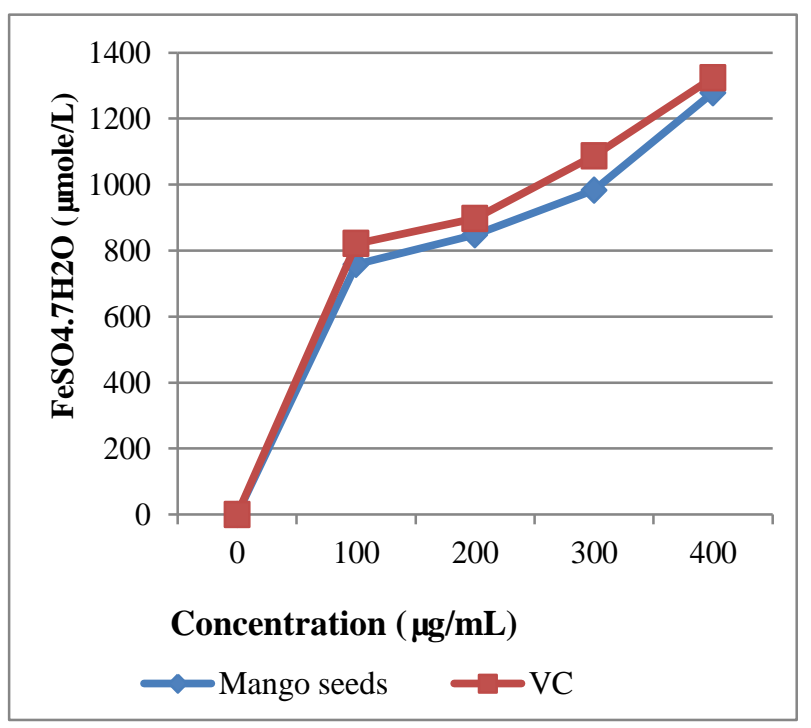

Figure 1. Ferric-reducing antioxidant power (FRAP) of M. indica waterlily kernel extract against that of Ascorbic Acid; treatment with different concentrations of M. indica extract and Ascorbic Acid showed a dose-dependent effect that was similar, with no significant differences $(\mathrm{p}>0.05)$.

TABLE I. RADICAL-SCAVENGING ACTIVITIES OF MANGIFERA INDICA WATERLILY KERNEL AND BHT

\begin{tabular}{lcc}
\hline Sample & Amount $(\mu \mathrm{g})$ & $\begin{array}{c}\text { DPPH scavenging } \\
\text { activity } \%\end{array}$ \\
\hline BHT & 50 & $57.53 \pm 0.6$ \\
& 100 & $85.50 \pm 0.9$ \\
& 150 & $89.07 \pm 0.7$ \\
& 200 & $92.33 \pm 0.7$ \\
& 250 & $98.17 \pm 0.8$ \\
M. indica & & \\
waterlily & 50 & $50.20 \pm 0.3$ \\
& 100 & $78.83 \pm 0.6$ \\
& 150 & $82.23 \pm 0.6$ \\
& 200 & $87.73 \pm 0.6$ \\
& 250 & $95.37 \pm 0.7$ \\
\hline
\end{tabular}

\section{DPPH Activity}

Table II shows the DPPH radical- scavenging activities of different concentrations of $\mathrm{M}$. indica waterlily kernel extract compared to control (Butylatedhydroxytoluene, BHT). At a concentration of $250 \mu \mathrm{g} / \mathrm{mL}$, the extract scavenged more than $95 \%$ of the DPPH radical, which was comparable to that of BHT $(98 \%)$. Its capacity for high scavenging activity may be attributed to the high amounts of TEP in M. indica waterlily kernel extract. This is in agreement with what Maciel et al. reported [16] $200 \mathrm{mg} / \mathrm{mL}$ of $\mathrm{M}$. indica extract produced scavenging activity of over $79.6 \%$. The antioxidant effects of $\mathrm{M}$. indica may be as a result of its electron-donating ability. It is expected that higher levels of polyphenols would possess an increased ability to donate electrons thus quenching free radicals, and our results are in agreement; high phenolic content of Mangifera indica waterlily kernel produced an equally higher radical-scavenging capacity in a dose-dependent manner.

There were significant increases in scavenging activities of both BHT and M. indica dose-dependently ( $\mathrm{p}$ $<0.05)$, and BHT showed slightly higher values at every concentration $(\mathrm{p}<0.05)$.

In the current study, a hydrolysis method was used to prepare the extract, which may have improved the antioxidant capacity of the extract as a result of increased release of the phenolic compounds. Already, Soong and Barlow [8] demonstrated that gallic acid and ellagic acid in their free forms produced higher antioxidant activities compared to their conjugated forms. They demonstrated that hydrolysis was a good method for releasing these compounds and thus increasing their antioxidant capacities. Furthermore, Nuutila et al. [14] showed that hydrolysis increased the release of phenolic acid and flavonoides.

\section{Identification of Phenolic Compounds of Mangifera Indica Waterlily Kernel}

Mango seeds are known to contain a mixture of polyphenols as phenolic acid, flavonoids and xanthones. To determine which of these were more abundant in the extract used in this study, chromatographic techniques were used as shown in Fig. 2. Reverse-phase HPLC was used to analyse the extract, which showed the presence of gallic acid (1), chlorogenic acid (2), epicatechin (3), 4hydroxybenzoic acid (4), mangiferin (5), syringic acid (6), EGC (7), p- coumaric acid (8), rutin (9), myricetin (10), quercetin (11) and apigenin (12) (Fig. 2). The compounds were confirmed by comparing those from the extract to the retention times of their standards, as shown in Table II.

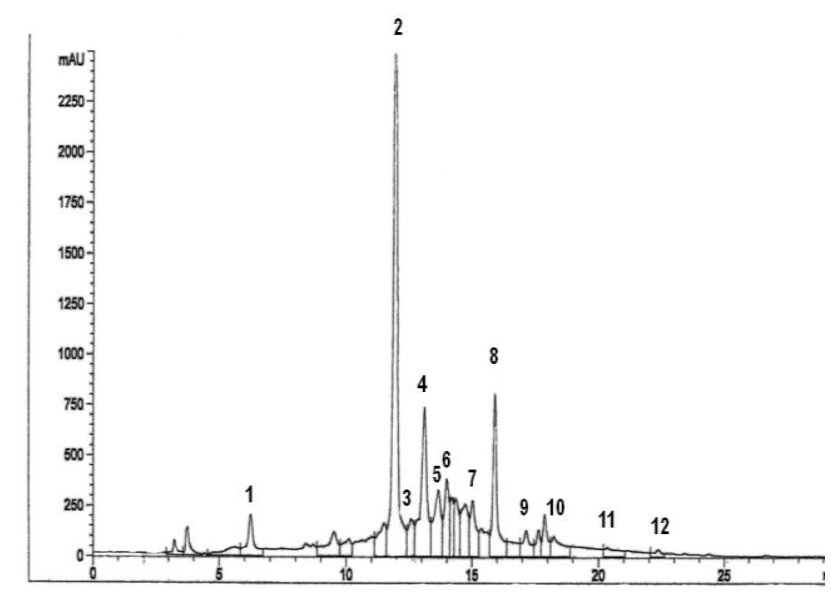

Figure 2. HPLC profile of phenolic compounds in M.indica waterlily kernel peak identification: 1, gallic acid; 2, chlorogenic acid; 3, epicatechin; 4, 4-hydroxybenzoic acid; 5, mangiferin; 6, syringic acid; 7 , EGC; 8, $P$-coumaric acid; 9, rutin; 10, myricetin; 11 , quercetin; 12 , apigenin.

Masibo and $\mathrm{He}$ [23] have reported that major phenolic acid identified in mango parts (pulp, peel, seed, leaf, and stem bark extracts) include gallic acid, methyl gallate, 
digallic acid, ellagic acid, $\beta$-glucogallin, and $\alpha$ gallotannin. In addition, Kim et al. [24] reported the presence of gallic acid, p- coumaric acid, coumaric acid, ferulic acid and p-OH-benzoic acid, while Ribeiro and Schieber [25] reported that gallic acid, ferulic, protocatechuic, caffeic, coumaric, ellagic and 4caffeoylquinic acids were the major compounds present in Mangifera indica peel, flesh and kernel. Following HPLC analyses, more structural information using LCMS (Liquid Chromatography Mass Spectrometry) was obtained for positive identification and to make up for shifts in retention times on HPLC. To confirm the result of HPLC identification, the structures and molecular formulas of the 12 phenolic compounds were determined from their electrospray ionization tandem mass spectrometry (ESI-MS) spectra (Table II).

TABLE II. PHENOLIC COMPOUNDS IDENTIFIED BY HPLC-ESI-MS AND THEIR QUANTITIES IN $M$. INDICA WATERLILY KERNEL

\begin{tabular}{llll}
\hline \hline $\begin{array}{c}\mathbf{t}_{\mathbf{R}} \\
(\mathbf{m n})\end{array}$ & \multicolumn{1}{c}{ Compound } & \multicolumn{1}{c}{ MW } & \multicolumn{1}{c}{$\begin{array}{c}\text { Relative } \\
\text { abundance }\end{array}$} \\
\hline 6.2 & Gallic acid & 170.12 & $4.1 \mathrm{E} 4$ \\
11.9 & Chlorogenic acid & 354.31 & $1.1 \mathrm{E} 7$ \\
12.6 & Epicatechin & 290 & $3.6 \mathrm{E} 4$ \\
13.0 & 4-hydroxybenzoic acid & 138.12 & $7.5 \mathrm{E} 7$ \\
13.6 & Mangiferin & 422.33 & $6.7 \mathrm{E} 4$ \\
13.9 & Syringic acid & 198 & $2.6 \mathrm{E} 5$ \\
15.0 & EGC & 306.27 & $7.4 \mathrm{E5}$ \\
15.9 & P-coumaric acid & 164.16 & $1.7 \mathrm{E5}$ \\
17.1 & Rutin & 610.16 & $5.1 \mathrm{E} 4$ \\
18.2 & Myricetin & 318 & $2.4 \mathrm{E5}$ \\
20.3 & Quercetin & 302 & $1.7 \mathrm{E6}$ \\
22.3 & Apigenin & 270 & $3.6 \mathrm{E5}$ \\
\hline
\end{tabular}

n.d. not detected in signed mode; ${ }^{a}$ Highest compound intensity in signed mode.

Following identification of the compounds using fullscan conditions, the extracted-ion at $\mathrm{m} / \mathrm{z}$ values corresponding to the $[\mathrm{M}-\mathrm{H}]-,[\mathrm{M}+\mathrm{H}]+$ ions of the studied compounds were analyzed. Already, Selles et al. [26] has demonstrated the use of structure characterization for HPLC quantitative determination of phenolic constituents from Mangifera indica stem bark including gallic acid, methyl gallate, mangiferin, 4hydroxy benzoic acid, catechin, epicatechin and propyl benzoate. Identification and quantification of Xanthone and flavonols including mangiferin, kaempferol and their related glycosides have also been reported in peels of Brazilian mango cultivars, which were detected in the negative mode $[\mathrm{M}-\mathrm{H}]-[9]$. In the current study, the identities of all compounds were confirmed by comparison of the data with those of standard compounds The corresponding UV-Vis and MS data for the 12 compounds identified were obtained and used in the structural characterization.

A study by Charrouf et al. [27] reported that phenolic compounds including gallic acid, protocatechuic acid, catechin and rutin were detected in negative mode at masses of 169, 153, 289 and $609 \mathrm{~m} / \mathrm{z}$, respectively using ions full scan of $[\mathrm{M}-\mathrm{H}]$ - which agreed with the masses in the current study. Whereas gallic acid, p-coumaric acid, ferulic acid, ellagic acid, kaempferol were detected in strawberry fruit at the same wavelength as in this study, 272, 326, 238, 368 and $266 \mathrm{~nm}$, respectively [28].

\section{E. Quantitative Analysis of Phenolic Compounds}

The quantitative analyses of the phenolic compounds in M.indica waterlily kernel extract was performed by HPLC. The concentration of each compound in the studied extract was determined by from the calibration equation of the corresponding standard and showed that EGC, chlorogenic acid, apiginin, epicatechin, rutin, pcoumaric acid, myricetin, mangiferin, 4-hydroxybenzoic acid, gallic acid, quercetin and syringic acid were present at concentrations of 21.8, 13.7, 3.2, 2.7, 2.5, 2.4, 2.0, 1.8, $1.2,1.1,0.8$ and $0.5 \mathrm{mg} / \mathrm{g}$ dry weight, respectively (Table III).

TABLE III. QUANTIFICATION OF PHENOLIC COMPOUNDS IN M.INDICA WATERLILY KERNEL USING HPLC-DAD

\begin{tabular}{|c|c|c|c|c|}
\hline Compound & Regression equation $^{\text {a }}$ & Correlation & coefficient & $\begin{array}{c}\text { Amount } \\
(\mathrm{mg} / \mathrm{g})\end{array}$ \\
\hline Gallic acid & $y=69.833 x+197.52$ & 0.9993 & & $1.11 \pm 0.04$ \\
\hline Epicatechin & $y=25.138 x+53.55$ & 0.993 & & $2.67 \pm 0.16$ \\
\hline$P$-coumaric acid & $y=87.467 x+299.64$ & 0.9959 & & $2.43 \pm 0.13$ \\
\hline Mangiferin & $y=83.324 x-36.381$ & 0.9982 & & $1.77 \pm 0.05$ \\
\hline Rutin & $y=23.167 x+52.143$ & 0.9947 & & $2.49 \pm 0.08$ \\
\hline Chlorogenic acid & $y=55.228 x+197.36$ & 0.9959 & \multicolumn{2}{|c|}{$13.66 \pm 0.5$} \\
\hline EGC & $y=4.514 x+13.672$ & 0.9984 & \multicolumn{2}{|c|}{$21.79 \pm 1.2$} \\
\hline 4-hydroxybenzoic & $y=222.13 x+775.25$ & 0.9985 & \multicolumn{2}{|c|}{$1.21 \pm 0.03$} \\
\hline Syringic acid & $y=90.205 x+626.65$ & 0.9985 & \multicolumn{2}{|c|}{$0.52 \pm 0.01$} \\
\hline Myricetin & $y=35.17 x+77.259$ & 0.9985 & \multicolumn{2}{|c|}{$1.98 \pm 0.06$} \\
\hline Quercetin & $y=45.627 x+327.55$ & 0.9996 & \multicolumn{2}{|c|}{$0.75 \pm 0.01$} \\
\hline Apigenin & $y=5.7729 x-5.72$ & 0.9978 & \multicolumn{2}{|c|}{$3.21 \pm 0.05$} \\
\hline Total & & & \multicolumn{2}{|c|}{$53.58 \pm 0.81$} \\
\hline
\end{tabular}

a y expresses the detection response (peak area mAU*s) and $\mathrm{x}$ the concentration for phenolic compounds (in $\mu \mathrm{g} / \mathrm{mL}$ ); amount (mean value \pm standard deviation; $\mathrm{n}=3$ ) 
Berardini et al. [29] demonstrated the amounts of phenolic compounds like mangiferin and kaempferol in peels of different mango (Mangifera indica L) cultivars to be 1.3 and $0.7 \mathrm{mg} / \mathrm{g}$, respectively. These are lower than those reported in the current study. The hydrolysis used in the current study could have increased the release and thus amounts of phenolic compounds detected [14], [30], [31]. Furthermore, the results obtained in the current study are higher than those reported for Mangifera indica stem bark by NúñezSellés et al. [32]. They demonstrated the presence of several phenolic compounds such as gallic acid, benzoic acid, methyl gallate, propyl gallate, mangiferin and catechin at concentrations of 208 $\mathrm{mg} / 100 \mathrm{~g}, 198 \mathrm{mg}, 445 \mathrm{mg}, 476 \mathrm{mg}$, and $7140 \mathrm{mg}$, respectively. The high amount reported in the current study could be due to the higher proportion of phenolic compounds found in peel compared to the stem bark.

This is supported by the report of Masibo and He [23] that mango peel is richer in polyphenols compared to that of pulp, leave, seed and steam bark.

Some studies have reported that mango peels are a rich source of polypenols [33], phenolic acid and flavonols [23], flavonol and xanthone, mangiferin [34]. A number of phenolic compounds have been reported in mango (Mangifera indica) peel including ellagic acid, mangiferin, mangiferin gallate, isomangiferin, isomangiferin gallate, quercetin, kaempferol, rhamnetin and their related conjugates [23]. Berardini et al. [21] established that the antioxidative capacity of the mango peel extract was higher than that of standard mangiferin and quercetin 3O-glucoside, thus suggesting that the antioxidative capacity of the peel extract cannot be attributed to a single component but to the synergistic effect of all the compounds present. In addition to their effects as antioxidant and anticancer agent, a study reported that phenolic acids such as gallic acid have antimicrobial activity for controlling dental caries and periodontal disease [35]. Another phenolic, Mangiferin, has a wide range of pharmacological effects including hypolipidimic, antidiabetic, anti-HIV, antitumor, immunomodulatory and antioxidant activities [36]. The functional effects of the $M$. indica could be attributable to its high antioxidant activity as shown in the present study, and therefore its potentials in neutralizing free radicals could have profound implications on oxidative stress.

\section{CONCLUSIONS}

The present study demonstrated that the extract obtained from M.indica waterlily kernel is a rich source of polyphenols (phenolic acid, flvonoides and xanthones). The antioxidant capacity of the M.indica waterlily kernel as determined by different antioxidant assays (DPPH and FRAP assays) exhibited a strong potency due to the presence of associated polyphenols with considerable amounts of phenols ( $86 \mathrm{mg} / \mathrm{g} \mathrm{M}$. indica waterlily kernel). EGC, chlorogenic acid, apiginin, epicatechin and rutin were found to be the major phenolic compounds among 12 phenolics identified and quantified. The study was able to show that hydrolysis produced higher concentrations of phenolic compounds likely due to increased release of the phenolics from the food matrix and finally their resultant good separation on chromatographic analyses.

\section{ACKNOWLEDGMENT}

The authors wish to thank Mustapha Umar Imam (Laboratory of Molecular Biomedicine, Institute of Bioscience, Universiti Putra Malaysia). This work was supported by a grant from Universiti Putra Malaysia.

\section{REFERENCES}

[1] C. Bierl, M. Forgione, and J. Loscalzo, "The antioxidant hypothesis," in Antioxidants and Cardiovascular Disease, M. G. Bourassa and J. C. Tardif, Eds., Springer Inc., USA, 2006, pp.87.

[2] D. V. Parke, "Nutritional antioxidants and disease prevention: Mechanisms of action," in Antioxidants in Human Health and Disease, T. K. Basu, et al., Eds., CABI Publishing: NY, USA, 1999, pp. 4.

[3] Z. He and W. Xia, "Analysis of phenolic compounds in Chinese olive (Canarium album L.) fruit by RPHPLC- DAD-ESI-MS," Food Chemistry, vol. 105, pp. 1307-1311, 2007.

[4] W. C. Willett, "Fruits, vegetables, and cancer prevention: turmoil in the produce section," Journal of the National Cancer Institute, vol. 102, pp. 510-511, 2010.

[5] I. Gulcin, M. T. Uguz, M. Oktay, S. Beydemir, and O. I. Kufrevioglu, "Evaluation of the antioxidant and antimicrobial activities of clary sage (Slaviasclarea L.)," Turkish Journal for Agriculture, vol. 28, pp. 25-33, 2004.

[6] J. A. Larrauri, P. Rupbrez, L. Bravo, and F. Saura-Calixto, "High dietary fibrepeels: Associated powders from orange and lime polyphenols and antioxidant capacity," Food Research International, vol. 29, pp. 751-762, 1996.

[7] C. M. Ajila, S. G. Bhat, and U. J. S. P. Rao, "Valuable components of raw and ripe peels from two Indian mango varieties," Food Chemistry, vol. 102, pp. 1006-1011, 2007.

[8] Y. Soong and P. J. Barlow, "Quantification of gallic acid and ellagic acid from longan (Dimocarpus longan Lour.) seed and mango (Mangifera indica L.) kernel and their effects on antioxidant activity," Food Chemistry, vol. 97, pp. 524-530, 2006.

[9] S. M. R. Ribeiro, L. C. A. Barbosa, J. H. Queiroz, M. Knodler, and A. Schieber, "Phenolic compounds and antioxidant capacity of Brazilian mango (Mangifera indica L.) varieties," Food Chemistry, vol. 110, pp. 620-626, 2008.

[10] S. H. Al-Sheraji, A. Ismail, M. Y. Manap, S. Mustafa, et al., "Functional properties and characterization of dietary fiber from mangifera pajang kort. Fruit pulp," Journal of Agricultural and Food Chemistry, 2011, vol. 59, pp. 3980-3985.

[11] F. A. Hassan, A. Ismail, A. Abdul Hamid, A. Azlan, and S. H. Alsheraji, "Characterisation of fibre-rich powder and antioxidant capacity of mangifera pajang K. fruit peels," Food Chemistry, vol. 126, pp. 283-288, 2011.

[12] W. Xu, F. Zhang, Y. Luo, L. Ma, et al., "Antioxidant activity of a water-soluble polysaccharide purified from," Pteridium Aquilinum. Carbohydrate Research, vol. 344, pp. 217-222, 2009.

[13] B. Yang, J. Wang, M. Zhao, Y. Liu, et al., "Identification of polysaccharides from pericarp tissues of litchi (Litchi chinensis Sonn.) fruit in relation to their antioxidant activities," Carbohydrate Research, vol. 341, pp. 634-638, 2006.

[14] A. M. Nuutila, K. Kammiovirta, and K. M. Oksman-Caldentey, "Comparison of methods for the hydrolysis of flavonoids and phenolic acids from onion and spinach for HPLC analysis," Food Chemistry, vol. 76, pp. 519-525, 2002.

[15] C. M. Ajila, M. Aalami, K. Leelavathi, and U. J. S. Prasada Rao, "Mango peel powder: A potential source of antioxidant and dietary fiber in macaroni preparations," Innovative Food Science and Emerging Technologies, vol. 11, pp. 219-224, 2010.

[16] L. F. Maciel, C. S. Oliveira, E. S. Bispo, P. Maria, and S. Miranda, "Emerald article: Antioxidant activity, total phenolic compounds and flavonoids of mangoes coming from biodynamic, organic and conventional cultivations in three maturation stages," British Food Journal, vol. 113, pp. 1103-1113, 2011. 
[17] J. A. Larrauri, P. Rupérez, B. Borroto, and F. Saura-Calixto, "Mango peels as a new tropical fiber: Preparation and characterization," Lebensmittel Wissenschaft und Technologi, vol. 29, pp. 729-733, 1996.

[18] A. Escarpa and M. C. González, "Approach to the content of total extractable phenolic compounds from different food samples by comparison of chromatographic and spectrophotometric methods," Analytica Chimica Acta, vol. 427, pp. 119-127, 2001.

[19] S. H. Al-Sheraji, A. Ismail, M. Y. Manap, S. Mustafa, et al., "Purification, characterization and antioxidant activity of polysaccharides extracted from the fibrous pulp of mangifera pajang fruits," LWT- Food Science and Technology, vol. 48, pp. 291-296, 2012.

[20] M. F. Abu Bakar, M. Mohamed, A. Rahmat, and J. Fry, "Phytochemicals and antioxidant activity of different parts of bambangan (Mangifera pajang) and tarap (Artocarpus odoratissimus)," Food Chemistry, vol. 113, pp. 479-483, 2009.

[21] N. Berardini, A. Schieber, I. Klaiber, U. Beifuss, et al., "7 Omethylcyanidin 3-O- $\beta$-D- galactopyranoside, a novel anthocyanin from mango (Mangifera indica L.) cv. 'Tommy Atkins' peels," Chemical Science, vol. 60, pp. 801-804, 2005.

[22] C. M. Ajila, S. G. Bhat, and U. J. S. P. Rao, "Valuable components of raw and ripe peels from two Indian mango varieties," Food Chemistry, vol. 102, pp. 1006-1011, 2007.

[23] M. Masibo and Q. He, "Major mango polyphenols and their potential significance to human health," Comprehensive Reviews in Food Science and Food Safety, vol. 7, pp. 309-319, 2008.

[24] Y. Kim, J. K. Brecht, and S. T. Talcott, "Antioxidant phytochemical and fruit quality changes in (Mangifera indica L.) following hot water immersion and controlled atmosphere storage," Food Chemistry, vol. 105, pp. 1327- 1334, 2007.

[25] S. M. R. Ribeiro and A. Schieber, "Bioactive Compounds in Mango (Mangifera indica L.)," in Bioactive Foods in Promoting Health: Fruits and Vegetables, R. R. Watson and V. R., Preedy, Eds., Elsevier Publishers, PA, USA, 2010, pp. 507.

[26] A. J. N. Selles, H. T. V. Castro, J. Agüero-Agüero, J. GonzálezGonzález, et al., "Isolation and quantitative analysis of phenolic antioxidants, free sugars, and polyols from mango (Mangifera indica L.) stem bark aqueous decoction used in Cuba as a nutritional supplement," Journal of Agricultural and Food Chemistry, vol. 50, pp. 762-766, 2002.

[27] Z. Charrouf, M. Hilali, O. Jauregui, M. Soufiaoui, and D. Guillaume, "Separation and characterization of phenolic compounds in argan fruit pulp using liquid chromatographynegative electrospray ionization tandem mass spectroscopy," Food Chemistry, vol. 100, pp. 1398- 1401, 2007.

[28] C. Mertz, V. Cheynier, Z. Günata, and P. Brat, "Analysis of phenolic compounds in two blackberry species (Rubus glaucus and rubus adenotrichus) by high-performance liquid chromatography with diode array detection and electrospray ion trap mass spectrometry," Jornal of Agricaltural and Food Chemistry, vol. 55, pp. 8616-8624, 2007.

[29] N. Berardini, R. Fezer, J. Conrad, U. Beifuss, et al., "Screening of mango (Mangifera indica L.) cultivars for their contents of flavonol O- and xanthone C- glycosides, anthocyanins, and pectin," Journal of Agricultural and Food Chemistry, vol. 53, pp. $1563-1570,2005$.

[30] M. Naczk and F. Shahidi, "Phenolics in cereals, fruits and vegetables: Occurrence, extraction and analysis," Journal of Pharmaceutical and Biomedical Analysis, vol. 41, pp. 1523-1542, 2006.

[31] T. Madhujith, M. Izydorczyk, and F. Shahidi, "Antioxidant properties of pearled barley fractions," Journal of Agricultural and Food Chemistry, vol. 54, pp. 3283-3289, 2006.
[32] A. J. NúñezSellés, H. T. V. Castro, J. Aguero-Aguero, J. Gonzalez-Gonzalez, et al., "Isolation and quantitative analysis of phenolic antioxidants, free sugars and polyols from mango (Mangiferaindica L.) stem bark aqueous decoction used in Cuba as a nutritional Supplement," Journal of Agricultural and Food Chemistry, vol. 50, pp. 762-766, 2002.

[33] N. Berardini, R. Carle, and A. Schieber, "Characterization of gallotannins and benzophenone derivatives from mango (Mangifera indica L. cv. "Tommy Atkins") peels, pulp and kernels by high-performance liquid chromatography/electrospray ionization mass spectrometry," Rapid Communication in Mass Spectrometry, vol. 18, pp. 2208- 2216, 2004.

[34] N. Berardini, M. Knödler, A. Schieber, and R. Carle, "Utilization of mango peels as a source of pectin and polyphenolics," Innovative Food Science and Emerging Technologies, vol. 6, pp. 443-453, 2005.

[35] M. Kang, J. Oh, I. Kang, S. Hong, and C. Choi, "Inhibitory effect of methyl gallate and gallic acid on oral bacteria," The Journal of Microbiology, vol. 46, pp. 744-750, 2007.

[36] N. Yoshimi, K. Matsunaga, M. Katayama, Y. Yamada, et al., "The inhibitory effects of mangiferin, a naturally occurring glucoxanthone, in bowel carcinogenesis of male F344 rats," Cancer Letters, vol. 26, pp. 163-170, 2001.

Hussah Abdullah was born on $25^{\text {th }}$ June 1974 at Dammam in Saudi Arabia. She had her early primary and secondary education in $8^{\text {th }}$ school and $41^{\text {st }}$ school in Dammam. She continued her pre-university education in $33^{\text {rd }}$ school in Dammam, and later received her Bachelor of Science (Good) in Botany Science in Dammam University on 2003. She worked as a laboratory technician before pursuing her Masters degree in Biochemistry and Biotechnology Engineering in International Islamic University Malaysia, under the King Abdullah Scholarship Scheme of the Saudi culture missions.

Mohammed was born in Kano state, Nigeria. He obtained his Bachelor Degree in Applied Biology from Bayero University, Kano in 1989. He worked as a lecturer at the department of Biological science, Bayero University Kano from 1990 to 1997, and also obtained his Masters degree in Food Biotechnology from University of Strathclyde Glasgow, United Kingdom in 1995. In 2005 he obtained his PhD in Enzyme and Food Biotechnology from Universiti Putra Malaysia, where is currently an Associate Professor at the Faculty of Food Science and Technology.

Abdullah was born on $15^{\text {th }}$ January 1947 at Malaysia. He had his early primary and secondary education in Malaysia, while his Bachelor degree was from University of Western Australia in 1973 and Masters degree from University of New England, New South Wales, Australia in 1975. He received his PhD from University of California, Davis in 1989. $\mathrm{He}$ is currently a Professor at Universiti Putra Malaysia, Faculty of Veterinary Medicine.

Mirghani first degree was in Biochemistry, while his Masters and $\mathrm{PhD}$ were in Applied Chemistry and Biochemistry, and Food Chemistry and Biochemistry, respectively. His current area of specialization is Fats and Oils Chemistry and Technology. He is currently an Associate Professor with the Department of Biotechnology Engineering, Faculty of Engineering at the International Islamic University Malaysia (IIUM), where he is also the Deputy Director; research \& Innovation; at the International Institute for Halal Research and Training (INHART) at IIUM. 